\title{
Multisensory Approach to Reading Skills of Dyslexic Students
}

\author{
R. Kamala \\ Ph.D. Scholar, Department of Educational Technology, Bharathidasan University, Tamilnadu, India.
}

\begin{abstract}
A single teaching strategy may not suitable for all students and the special needs students require differentiated teaching strategy. Learning through the senses is the best way of learning anything. Teaching of reading in English is a complex phenomenon for the teachers who are teaching the normal students. Furthermost, teaching the skill of reading to the reading disabled students is much more complicated task for the English teachers. But this reading disabled student can also be taught to read in English effectively by adopting the multisensory approach. Henceforth, the article focuses on the teaching of reading to the dyslexics through multisensory approach.
\end{abstract}

Keywords: Reading Skills. Dyslexic, Multisensory Approach

\section{Introduction}

Learning takes place through the senses. It is a well know fact that senses are the gate ways of learning. The purpose of learning any language is to develop the four skills, namely listening, speaking, reading, and writing. English is a link language in India and it is considered as a second language which occupies an eminent place among the languages in India. Hence, teaching of English is a prime importance to the Indian students to use it effectively in their day-to-day life and acquire knowledge in all the fields. In India, English has been thought as a knowledge subject rather that skill subject. Often, the first three skills such as listening, speaking and reading are neglected in the teaching learning process of the English classrooms. More importance is given to the writing skills and the skill of reading has been left unnoticed in the Indian language classrooms. Learning to read in English becomes a thrush-hold to acquire knowledge from various sources. Teaching of reading in English is a complex phenomenon for the teachers who are teaching to the normal students. Furthermost, teaching the skill of reading to the reading disabled students (Dyslexics) is much more complicated task for the English teachers. But the students with reading disabilities can also be taught to read in English effectively by adopting the multisensory approach.

\section{Reading Disability}

Dyslexia has been defined and conceptualized in different ways in different countries. Dyslexia is one of the Specific Learning Disabilities (SpLD) and otherwise referred as Reading Disabilities. SpLD is a group of neurodevelopment disorders manifesting as persistent difficulties in learning to efficiently read (Dyslexia), Write (Dysgraphia) or perform mathematical calculation (Dyscalculia) despite normal intelligence, conventional schooling, intact hearing and vision, adequate motivation and socio-cultural opportunity (Lagae, 2008). Current literature indicates that $10-14 \%$ of the 416 million children in India have Learning Disabilities (Krishnan, 2007; Krishnakumar, 1999; Mehta, 2003) making it the most widespread disability (Suresh and Sebastian, 2003; Tandon, 2007). It is estimated that India has five students with SpLD in every average-sized class (Thomas, Vhanutej and John, 2003). Dyslexia is the most common and most carefully studied of the SpLDs, affecting $80 \%$ of all those identified as Learning Disabled (Karande, Sawant, Kulkarni, Galvankar, and Sholapurwala, 2005).

The word dyslexia is derived from the two Greek Morphemes "dys" (poor/inadequate) and "lex" (words/language) which means "difficulty with language" or "trouble with words" (cox, 1985). The term dyslexia which is otherwise known as specific reading disabilities, typically have average to above average intelligence. They may have difficulties with reading, spelling, understanding language they hear, or expressing them clearly in speaking or in writing. An unexpected gap exists between their potential for learning and their school achievement.

The International Dyslexia Association (1998) defines "dyslexia is a learning disability characterized by problems in expressive or receptive, oral or written language. Problems may emerge in reading, spelling, and writing, speaking or listening. Dyslexia is not a disease, it has no cure. Dyslexic describes a different kind of mind, often gifted and productive, that learns differently. Dyslexia is not the result of low intelligence. Intelligence is not the problem. An unexpected gap exists between learning aptitude and achievement in schools. The problem is not behavioural, psychological, motivational or social. It is not a problem of vision; people with dyslexia do not 'see backwards'. Dyslexia results from differences in the structure and functions of the brain. 
People with dyslexia are unique, each having individual strengths and weakness. Many dyslexics are creative and have unusual talents in areas such as art, athletics, architecture, graphics, electronics, mechanics, drama, music or engineering. Dyslexics often show special talent in areas that require visual, spatial, and motor integration. Their problems in language processing distinguish them as a group this means that the dyslexics have problems in translating language into thoughts (as in listening or reading) or thought into language (as in writing or speaking)."

\section{Symptoms Of Dyslexia}

The signs of dyslexia differ from individuals to individuals but the most common symptoms of dyslexia are listed below:

- Has difficulty in learning to read

- Confuses with similar looking letters (b as d, m as w)

- Mispronounces the words while reading

- $\quad$ Skips the words while reading loudly

- Confuses similar-looking words (e.g., beard/bread)

- $\quad$ Lacks consistency in reading words

- Omits prefixes or suffixes of words while reading

- Reading level is below the grade level

- Reversals in the reading of letters such as $\mathrm{n}$ for $\mathrm{u}, \mathrm{p}$ for $\mathrm{q}, \mathrm{d}$ for $\mathrm{b}$ and also monosyllabic word reversals such as know for on, was for saw.

- Omissions and additions of words in oral sentence reading.

- Excessive slowness in reading

- Poor retention of material that has been read

- Difficulty with spontaneous writing and writing to dictation

- Has problems in associating letter with sounds

- Finds difficulty to blend the sounds into words

- Has inadequate phonological awareness

- Has difficulty in reading the charts in a sequential order

- Academic performance is below than the grade level

\section{Multisensory Approach At A Glance}

Multisensory approach utilizes more than one sense in the teaching process to enhance the learning process of the students. When learning takes place through more than one sense the students' learning capacities and the retention of the learnt materials have been improved.

Most of the teaching in schools is done using either visual or auditory mode (visual or hearing). Multisensory approach is otherwise known as VAKT Method. The four modalities of learning styles have been summarized by the acronym VAKT, for: Visual, Auditory, Kinesthetic and Tactile.

- Visual: That which you see.

- Auditory: That which you hear.

- Kinesthetic: The tactile - where the child touches and handles objects.

The best teaching method is to involve the use of more of the student's all the senses, especially the use of touch and movement (kinesthetic). This will give the student's brain tactile and kinesthetic memories to hang on to, as well as the visual and auditory ones.

\section{Teaching Reading Through Multisensory Approach}

Reading is a fundamental skill which is very important for academic attainment of knowledge. Reading is translating the written word into speech sounds. Its acquisition is not as simple and automatic for dyslexics. Reading consists of the following components:

- Phonemics awareness (knowing that words are made up of sounds)

- Phonics (links between sounds and letters)

- Vocabulary (what words mean and how to say them)

- Fluency (the ability to read accurately at an adequate phase)

- Reading comprehension (the ability to understand what you read)

Multisensory teaching built on learner strong channels while also developing the weaker ones. It involves making clear links between the visual, auditory, kinesthetic and tactile senses (VAKT). This means that an activity should include at least two of the senses: seeing something (visual); hearing something related to what 
you is seen (auditory); some form of related movement of muscles, for example speaking or writing (Kinesthetic) and touching or feeling something (Tactile). The findings of the research in the field of dyslexia stated that for most of the dyslexic students have great difficulty in learn to read and problems in mastering the reading skills. This does not mean that the students with reading disabilities are not capable of developing reading skills. The dyslexic students can be taught to read effectively but they need a different strategy to develop the reading skills. Multisensory approach, developed by Orton and Gillingham, is one of the suitable approaches to teach reading to dyslexics. One of the pre- requisite skills for learning to read is to acquire knowledge about alphabet knowledge and phonological awareness which includes mastering the shapes of the alphabets and letter - sound correspondence and phonemic awareness. Teaching through multi-sensory makes the dyslexic students to learn these skills in an easy way. For instance, dyslexics often confuses with the similar looking letters (b and d), this confusion can be easily solved by making the students to use all their learning modalities (VAKT). The letters should be presented visually (visual modality) to the students, then the letters should be traced (kinetic and tactile) in their hands or plastic letters and the letter name and sounds are orally (Auditory mode) presented to the students.

\section{Conclusion}

Dyslexia is a language-based disability in which students have difficulty with specific language skills, particularly reading. The International Dyslexia Association also states that dyslexic students generally experience problems with other language skills such as spelling, writing, and pronouncing words. However, with appropriate teaching methods, these students can be taught successfully. Hence multisensory approach is a frequently used intervention method for students with reading disabilities. It employs two or more sensory modalities simultaneously (visual, auditory, tactile, and kinesthetic). Thus, it provides multiple pathways for helping students to learn alphabetic patterns and words more effectively than any other approach.

\section{Acknowledgement}

I acknowledge that the paper titled "Multisensory Approach to Reading Skills of Dyslexic Students" is a position paper, which is original contribution by the Author to the existing literature. The above said article is not submitted to any other journal for publication.

\section{References}

[1]. Davis, Ronald D. (1999), The Gift of dyslexia, Berkley Publishing Group, New York.

[2]. Gillingham, A., \& Stillman, B. W. (1960). Remedial Training for Children with Specific Disability in Reading, Spelling and Penmanship (7th ed.). Cambridge, MA: Educators Publishing Service.

[3]. International Dyslexia Association (2000), Dyslexia Basics, Just the Facts, The International Dyslexia Association website, http://www.interdys.org/fact\%20sheets/Basics\%20FS\%20N.doc, Accessed July 292013.

[4]. Karanth \& Rozario (Eds.), Learning Disabilities in India: Willing the Mind to Learn (pp. 30- 43). New Delhi: Sage Publications.

[5]. Madhuri Kulkarni, Sunil Karande, Anjana Thadhani, Hetal Maru and Rukhshana Sholapurwala . Educational Provisions and Learning Disability. Indian Journal of Pediatrcs, volume73- September, 2006 .p. 789-793.

[6]. Ramaa, S., \& Gowramma, I. P. (2002). A Systematic Procedure for Identifying and Classifying Children with Dyscalculia among Primary School Children in India. Dyslexia, 8, 67-85.

[7]. Rao, L. G. (2008). Education of Persons with Intellectual Disabilities in India. Salud Publica de Mex, 50 (suppl. 2), S205-S212

[8]. Rashmi Agrawal . Learning Disabilities; Teaching Learning Strategies. Shipra Pub. New Delhi. 2010

[9]. Ritchey, K. D., \& Goeke, J. L. (2006). Orton-Gillingham and Orton-Gillingham- Based Reading Instruction: A Review of Literature. The Journal of Special Education, 40(3), 171-183.

[10]. Sanders, M. (2001). Understanding Dyslexia and the Reading Process: a Guide for Educators and Parents. Boston: Allyn \& Bacon.

[11]. Shaywitz, Sally M.D. (2003), Overcoming Dyslexia: A New and Complete Science-Based Program for Reading Problems at any level, Knoph, Alfred A., New York.

[12]. Sunil Karande, Sulaxna, Madhuri Kulkarni, Sandeep Kanchan and Rukhshana Sholapurwala. "Cognition in Specific Learning Disability" Indian journal of Pediatrcs, volume72- December, 2005 .p1029-1033

[13]. Umadevi. M. R. Special Education; A Practical Approach to Educating Children with Special Needs. Neelkamal Pub . New Delhi. 2010 